\title{
Mental healthcare in Uganda: desperate challenges but real opportunities
}

\author{
Andrew Molodynski, ${ }^{1}$ Christina Cusack ${ }^{2}$ and Jurua Nixon ${ }^{3}$
}

\begin{abstract}
'Chair, World Association of Social Psychiatry Working Group on Coercion; Department of Psychiatry, Oxford University, UK Oxford Health NHS Foundation Trust, Oxford University, UK, mailandrew.molodynski@ oxfordhealth.nhs.uk Trust, UK

${ }^{3}$ Hear International, Arua Uganda

Conflicts of interest. AM is supporting the Mental Disability Advocacy Centre in a campaign to improve standards of mental healthcare in Uganda.

Recent reports have highlighted human rights concerns in Ugandan mental healthcare. This article describes the current situation in terms of healthcare funding and provision, concerns regarding legislation, and health inequalities. Possible reasons for the difficult situation are briefly discussed, including the economy, pervasive stigma and ongoing unrest in the region. We then describe some encouraging initiatives in Uganda that are empowering those with mental health problems to have a better quality of life and identify opportunities for change.
\end{abstract}

Uganda is a low-income country with a population of 38 million. After brutal periods of unrest following independence in 1964 it has enjoyed more stability recently. There has been significant progress on key measures of welfare and Uganda has surpassed its millennium development goals. Rates of poverty have reduced from $33.8 \%$ in 1998 to $19.5 \%$ in 2012 and life expectancy has risen from 44 in 1997 to 59 in 2014 (World Bank, 2016). While these represent major gains they are also indicators of the remaining challenges. Large areas are remote and the region suffers ongoing conflict and the effects of previous conflict.

Uganda spends $9.8 \%$ of gross domestic product on healthcare, or US\$146 annually per person. Less than $1 \%$ of this goes into mental healthcare, compared with $10 \%$ in the UK (World Health Organization, 2016). Ugandan mental health services have been characterised as inadequate, with little or no community care and in-patient services that are unable to meet demand. The World Health Organization (2006) estimates that $90 \%$ of people with mental illness receive no treatment. The situation is exacerbated by many skilled healthcare workers leaving Uganda to work in high-income countries, reducing what had been described as a highly skilled and motivated workforce.

\section{Mental health services}

There is no national coverage of community mental healthcare. A network of 28 out-patient facilities can provide follow-up care, but they are thinly spread and often starved of funds for even essential medication. A 2006 survey found that only $57 \%$ of clinics had at least one psychotropic medication in each class (World Health Organization, 2006). Many users have epilepsy rather than mental illness.

The majority of national mental health funding is invested in the national mental health hospital at
Butabika. It was established in 1955 and has 500 beds, although there is frequently overcrowding. Its annual budget is US\$2.25 million and it has approximately 430 staff (Emerald Project, 2016). There are no data regarding average length of stay or diagnostic mix. There are no reserved areas for children. Significant concerns have been raised about conditions, including detention without assessment, the prolonged and dehumanising use of seclusion, and very low levels of specialist staffing. The Mental Disability Advocacy Centre (MDAC) released a highly critical report in 2014. It highlighted the conditions of seclusion rooms, with many having no toilet, meaning that patients are forced to lie, often naked, on the same floor that they urinate and defecate on. The report also highlighted improper admission processes, with no distinction being made between compulsory and voluntary admissions and the lack of psychological interventions and heavy reliance on pharmacological treatment, often with severe sideeffects (Mental Disability Advocacy Centre, 2014).

Services of all types are disproportionately concentrated around the capital, with those living in much of the country having little access to mental healthcare.

\section{Barriers to access to effective care}

A number of factors undoubtedly interact to perpetuate this situation. The economy is crucially important. Uganda has made significant strides in reducing poverty over recent years and this has translated into greater investment in healthcare overall. However, funding remains low by international standards and the proportion allocated for mental healthcare disproportionately so. Many countries fund mental health services at around $10 \%$ of overall health spend. In Uganda this figure is just $1 \%$ (Ssebunnya et al, 2010). In this context it is not possible to provide humane, person-centred care or even the most rudimentary care to the majority of the population. There are simply not enough trained staff and insufficient availability of effective treatments.

Demand is significant. Estimates suggest that up to $35 \%$ of Ugandans suffer from a mental disorder and $15 \%$ require treatment (Ndyanabangi et al, 2004). This is likely to be an underestimate given international norms, relatively recent highintensity conflicts and ongoing regional civil unrest.

Several issues act to compound these problems. Traditional beliefs regarding causation mean that many people with mental health disorders do not present for treatment. Okello \& Neema (2007) 
describe the importance many people ascribe to spirits and witchcraft in mental illness. This will often lead to individuals seeking traditional healers, or being taken to them under coercion. Traditional healing can be patient-centred and caring, but often will include such things as chaining or tying for periods while the spirits are 'warded off'. It has been reported that as many as $80 \%$ of those within Uganda's mental hospitals have previously been to a traditional healer, often delaying the onset of evidence-based care and exposing the individual to coercive practice.

Stigma is a powerful force everywhere (Cox, 1979; Sartorius, 2007). Uganda is no different and the evidence suggests stigma is a pervasive societal issue and barrier to treatment. Ssebunnya et al (2009) looked at the relationship between mental illness, stigma and poverty in Uganda. Detailed interviews with over 100 stakeholders in health and social care, government and the media revealed widespread stigmatising attitudes, such as this from a senior clinician:

. because whenever we are buying drugs, again they say but for who? You know, so it becomes a bit of a problem ... even now in the administration, apart from us who are medical, the other people who are non-medical look at those people as mad ... you know ... they think it is wastage of money to buy them drugs. So it becomes a bit of big problem. (SSI, hospital medical superintendent, urban district)

It is easy to see why budgets are so low if it is commonly believed by funders that the mentally ill are a 'lost cause'. The effects of poverty are significant also, with people who are mentally ill often not being offered employment, being unable to access credit for equipment, land or livestock, and not being able to claim state assistance. They may thus be too poor to pay for travel to clinics or for the costs of medication. Families are affected too, with relatives often having work disrupted by the need to care. Children are less likely to attend school, creating an inter-generational burden.

The minority of people who do receive state mental healthcare will generally do so at Butabika Hospital and be subject to overcrowding, poor conditions and coercion, as outlined in the MDAC report and other publications (Cooper et al, 2010). While the individual may finally receive some form of treatment, the trauma involved may have additional long-term consequences. There are no separate facilities for children. The prevalence of coercive treatment is supported by the continuation of outdated legislation that is highly stigmatising, contains few safeguards and is often ignored.

\section{Ways forward}

New legislation has been in preparation for some years but its introduction has been repeatedly delayed. It contains important advances, such as stipulations for a scrutiny body and mechanisms for appeal, but it still leaves many gaps, such as the lack of definition of a mental illness and the provision for an individual to be held in seclusion (often without clothes, adequate food or fluids, or other basic needs) for up to 8 days without seeing a mental health worker of any kind. The proposed scrutiny arrangements are an improvement but it is hard to see how they will be carried out, given the critical workforce situation.

There have been a handful of positive initiatives using different approaches to support people who are mentally ill and their families, with the dual aim of reducing disability and reducing poverty. Basic Needs is a charity that works to empower individuals by assisting them to set up small businesses and access training (Basic Needs, 2015). This in turn can lead to improved conditions for their families and offer the realistic possibility of accessing treatment. An initiative in Mayuge, rural Uganda, to integrate mental healthcare into primary healthcare met significant resource barriers but did report progress on the part of those supported and the development of strong service user support (Petersen et al, 2011).

The recent announcement by GlaxoSmithKline that it will not pursue patents in poorer countries and allow for much cheaper generic products is welcome in the context described above, where medications are not available for financial reasons.

\section{Conclusions}

High-income countries with developed and established services have many advantages and a decent level of care is generally available. These systems, however, are complex and hard to change, and often not patient focused. As Uganda makes progress with increasing life expectancy and reducing poverty, increases in mental health budgets should be possible, with a reduction in the inequality between mental and physical healthcare. If the government can pay heed to the international concerns regarding human rights (and accept the significant support on offer), improve and adopt its draft Mental Health Bill, and work with pharmaceutical companies to increase drug availability, then things could change reasonably quickly.

While the challenges are substantial, there is an opportunity for a new kind of response to mental health need that is unfettered by the expectations and arrangements of previous decades. This healthcare could be cost-effective, locally led by both community members and people with mental illness (indeed, the two overlap substantially), and most importantly be sustainable in areas where it is likely that the economy will always be an issue. This model need not be a watered down or inferior version of that in wealthy countries, but something genuinely different - grounded in communities, minimising the need for institutional care, and linking closely with functional recovery through work and family networks.

\section{References}

Basic Needs (2015) Our approach. Web page at http://www. basicneeds.org/our-approach (accessed 9 June 2016).

Cooper, S., Ssebunnya, J., Kigozi, F., et al (2010) Viewing Uganda's mental health system through a human rights lens. International Review of Psychiatry, 22, 578-588. DOI https://doi.org/10.3109/09 540261.2010.536151. 
Cox, J. L. (1979) Amakiro: a Ugandan puerperal psychosis? Social Psychiatry, 14, 49-52.

Emerald Project (2016) Butabika National Mental Health Hospital. Available at http://www.emerald-project.eu/the-group/consortium/ butabika-national-referral-and-teaching-mental-hospital (accessed 6 June 2016).

Mental Disability Advocacy Centre (2014) Psychiatric Hospitals in Uganda: A Human Rights Investigation. MDAC.

Ndyanabangi, S., Basangwa, D., Lutakome, J., et al (2004) Uganda mental health country profile. International Review of Psychiatry. $16,54-62$.

Okello, E. S. \& Neema, S. (2007) Explanatory models and helpseeking behavior: pathways to psychiatric care among patients admitted for depression in Mulago Hospital, Kampala, Uganda Qualitative Health Research, 17, 14-25.

Petersen, I., Ssebunnya, J., Bhana, A., et al (2011) Lessons from case studies of integrating mental health into primary health care in South Africa and Uganda. International Journal of Mental Health Systems, 5, 8. DOI https://doi.org/10.1186/1752-4458-5-8.
Sartorius, N. (2007) Stigma and mental health. Lancet, 370, 810-811. Ssebunnya, J., Kigozi, F., Lund, C., et al (2009) Stakeholder perceptions of mental health stigma and poverty in Uganda. BMC International Health and Human Rights, 9. DOI https://doi. org/10.1186/1472-698X-9-5

Ssebunnya, J., Kigozi, D., Kizza, D., et al (2010) Integration of mental health care in a rural district in Uganda. African Journal of Psychiatry, 13, 128-131. Available at http://www.ncbi.nlm.nih.gov/ pubmed/20473474 (accessed 6 June 2016).

World Bank (2016) World databank (online). Available at http:// www.worldbank.org/en/country/uganda/overview (accessed 6 June 2016).

World Health Organization (2006) WHO-AIMS Report on Mental Health System in Uganda, WHO and Ministry of Health, Kampala, Uganda. Available at http://www.who.int/mental_health/uganda_ who aims report.pdf (accessed 6 June 2016).

World Health Organization (2016) Country overview (online). Available at http://www.who.int/countries/uga/en (accessed 6 June 2016).

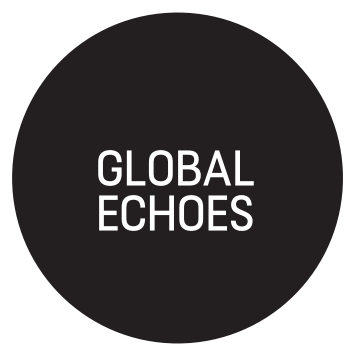

\title{
'I chained him to protect him from the spirits.' What are the challenges for psychiatrists in India?
}

\author{
Sukhmeet Singh
}

\section{PSYCHIATRY} UNDER RESTRICTIVE CONDITIONS
Approximately $20 \%$ of the adult Indian population are affected by a psychiatric disorder that requires intervention from a mental health professional (Math \& Srinivasaraju, 2010). In spite of this, the provision of mental healthcare is poor. Therefore, to learn more, between July and August 2014 I undertook a 4-week elective at the Psychiatry Department of Sawai Man Singh (SMS) Hospital in Jaipur, Rajasthan, India. The Psychiatry Department was founded in 1952. It has a total of 332 beds, with nearly 20000 patients admitted per year and an attendance of nearly 100000 annually at the out-patient department.

I wanted to go to India after reading a report about someone named Keshava, in Davangere district, Karnataka (Nagaraj, 2012). He was diagnosed with schizophrenia in his early 20s. Once his second course of medication had finished, his family had no money to pay for more and were not aware of the availability of free antipsychotics. They felt they had no choice but to handcuff him and when that was not enough to contain his behaviour they took to bricking him up in a room. There, deprived of sunlight and a toilet, the man remained for the next decade. People in the village began to forget about his existence and when local journalists attempted to investigate what had happened to this missing person, his mother informed them that he had died. Once his case had been reported in the local news media, regional officials took action and arranged for his admission.

\section{Consequences of stigma and discrimination}

When I came to India I did not expect that I would encounter any extreme cases like that of Keshava. Unfortunately, I did. I met a 30-year-old man on a round of the admissions ward. His mother had brought him to hospital because she said that his mind was 'broken'. She said that the problems had started 14 years ago but had recently worsened. The senior resident moved the patient's shirt downwards to reveal an iron chain tied around the patient's neck, kept in place by a padlock. The patient's mother stated that she had put the chain on only for the last $2 \frac{1}{2}$ months. Given the amount of rust on the chain I found that hard to believe. She explained that she 'chained him to protect him from the spirits', which she believed were the cause of the symptoms. The resident also found marks on the patient's wrists and ankles, presumably from shackles. The patient's mother was told to remove the chain around his neck but she was not able to due to the rust in the padlock.

The patient was not able to concentrate. He openly responded to hallucinations, was laughing and repeated the questions that the staff asked him. On discussion with the residents they stated that his prognosis would likely be very poor because of 